\title{
LEGISLAÇÃo DE PROPRIEDAdE INDUSTRIAL DO BRASIL e México no contexto do Acordo Trips e da EPIDEMIA DA AIDS: UM ESTUDO COMPARATIVO ${ }^{(1)}$
}

\author{
INDUSTRIAL PROPERTY LAW OF BRAZIL AND MEXICO IN THE CONTEXT \\ OF TRIPS AGREEMENT AND AIDS EPIDEMY: A COMPARATIVE STUDY
}

\author{
Julio Cesar Acosta-Navarro* \\ Maria Cristina Cacciamali** \\ Amaury P. Gremaud*** \\ Silvia Cárdenas-Prado****
}

\section{RESUMO}

Este trabalho teve o objetivo de analisar retrospectivamente o significado da interseção de dois fenômenos sociomodernos. Em primeiro lugar, a epidemia de HIV/AIDS (Vírus da Imunodeficiência Humana/Síndrome de Imunodeficiência Adquirida), com suas características históricas pouco usuais e alta letalidade; e, por por sua vez, a intrusão de leis de propriedade intelectual na sociedade, como o Acordo Trips (Trade Related Intellectual Property Subjects), com amplas repercussões sobre a saúde pública, sendo aqui tratados especificamente os casos de Brasil e México. Ambos os países modificaram suas leis de propriedade intelectual (LPI) para implementar o Acordo Trips (e, no caso do México, também o Nafta) nas últimas duas décadas, levando a patamares mais elevados de proteção de propriedade intelectual no México, quando comparado ao Brasil. Essas

(*) Doutor, Faculdade de Medicina, Universidade de São Paulo (FM/USP); Doutor, PROLAM-USP. Instituto do Coração (InCor), FM-USP. São Paulo/SP - Brasil. E-mail: jnavarro_2@hotmail.com. $\left.{ }^{(*}\right)$ Livre-docente, Universidade de São Paulo; Pós-Doutora, Massachusetts Institute of Tecnology (Estados Unidos); Doutora, Faculdade de Economia, Universidade de São Paulo. São Paulo/SP-Brasil. $\left.{ }^{* \star *}\right)$ Doutora, Faculdade de Economia, Universidade de São Paulo. São Paulo/SP - Brasil. $\left.{ }^{\star * \star \star *}\right)$ Especialista em Medicina, Associação de Medicina Intensiva. Médica, Instituto de Psiquiatria, FM-USP. São Paulo/SP - Brasil.

Texto recebido em 19.04.12. Revisado em 06.06.12. Aprovado em 07.06.12.

(1) Baseado na tese "Acordo TRIPS e suas repercussões sobre o acesso a medicamentos. O caso do HIVIAIDS no Brasil e no México: 'direito de patente' vs. 'direito à vida"', apresentada junto ao Programa de Pós-Graduação de Integração da América Latina (PROLAM) da Universidade de São Paulo (USP), como requisito para obtenção do título de Doutor em Integração da América Latina (2011). 
mudanças, porém, podem ter contribuído, no caso do México, para um menor rendimento e eficácia do seu programa de combate à epidemia de AIDS HIV já que, para dar uma cobertura mais adequada de tratamento com medicamentos antirretrovirais (ARVs) a sua população, teve que enfrentar maiores dificuldades para sua aquisição. No substrato dos fatores causais dessas divergências, podem ser considerados diversos fatores de natureza econômica e política, dentre eles a maior ou menor magnitude da influência política dos Estados Unidos e interesses econômicos de suas empresas transnacionais sobre ambos os países.

\section{Palavras-chave:}

Acesso a Medicamentos ARVs; Acordo Trips; AIDS; Propriedade Intelectual; Saúde Pública.

\section{ABSTRACT}

This work analyzed retrospectively the meaning of the intersection of two modern social phenomena. Firstly, the epidemic of HIVIAIDS (Human Immunodeficiency Virus/Acquired Immunodeficiency Syndrome), with its unusual historical characteristics and high lethality; and, on the other hand, the intrusion of intellectual property laws in society as the Trips (Trade Related Intellectual Property Subjects) Agreement, that has far-reaching consequences on public and here we treated specifically the cases of Brazil and Mexico. Both countries changed their intellectual property laws to implement the Trips Agreement (and in the case of Mexico also Nafta) during the last two decades, leading to higher levels of intellectual property protection in Mexico compared to Brazil. However these changes may have contributed in the case of Mexico to a lower performance and effectiveness of its program to combat the epidemic of HIVIAIDS, since to give a more adequate coverage of treatment with antiretroviral drugs (ARVs) for its population, had to face major difficulties for purchasing these medicines. In the substrate of the causal factors of these differences, it could be considered several of economical and political nature, among them the greater or lesser magnitude of influence U.S. policy, the economic interests of multinational corporations on both countries.

\section{Keywords:}

Access to ARVs Drugs; AIDS; Intellectual Property; Public Health; Trips Agreement.

\section{INTRODUÇÃO}

Durante as últimas duas décadas, a sociedade testemunhou dois fenômenos sociais que deixaram uma profunda reflexão para esta e as próximas 
gerações. Em primeiro lugar, a epidemia de HIVIAIDS (Vírus da Imunodeficiência Humana/Síndrome de Imunodeficiência Adquirida), com suas características históricas pouco usuais e alta letalidade; em segundo lugar, a intrusão de normas de propriedade intelectual na vida cotidiana, como o Acordo Trips (Trade Related Intellectual Property Subjects) - integrante de um conjunto de acordos assinados em 1994 que encerrou a Rodada Uruguai e criou a Organização Mundial de Comércio (OMC) e que estabeleceu padrões mínimos quanto à proteção da propriedade intelectual -, com amplas repercussões sobre a saúde pública, assim como sobre o desenvolvimento econômico e tecnológico dos países.

Atualmente, mais de $95 \%$ das pessoas infectadas pelo HIV (em torno de 55 milhões) vivem em países em desenvolvimento, onde se registraram $95 \%$ das mortes causadas pela AIDS, como mostram as estatísticas. A maioria dessas mortes ocorreu entre adultos jovens, que normalmente estariam em seu máximo pico produtivo e de reprodução, causando uma importante perda econômica e de bem-estar social. ${ }^{(2)}$ Em países desenvolvidos, a introdução de tratamento antirretroviral (ARV) altamente ativo e a disponibilidade de drogas para as infecções oportunistas levaram a uma redução substancial na mortalidade pela AIDS. Diversos fatores inter-relacionados determinam o acesso às drogas essenciais, incluindo aquelas para tratar o HIV e as infecções oportunistas. Entre eles estão: uso apropriado, aspectos econômicos, seleção da droga, legislação e regulação, fabricação, pesquisa e decisões de desenvolvimento.(3) Como a epidemia de HIVIAIDS é bem recente na história médica, a maioria das drogas criadas especialmente para tratar a infecção pelo HIV e mudar o curso evolutivo fatal da AIDS já está sob patentes. Isso torna o tratamento contra a AIDS menos acessível em comparação àqueles para os quais existem alternativas de medicamentos genéricos. A proteção de patentes, nesse caso, garante direitos exclusivos para uma invenção e evita a concorrência de genéricos. Esta certamente é uma das razões possíveis para a limitada disponibilidade de medicamentos e a dificuldade no cumprimento do tratamento. Nesse contexto, muitos estudiosos, como Satyanarayana, consideram que o Acordo Trips seja responsável pela crise global atual de medicamentos para o HIV/AIDS. ${ }^{(4)}$

O objetivo deste trabalho é analisar retrospectivamente qual foi a influência da legislação sobre propriedade industrial (LPI) do Brasil e do México sobre o acesso a medicamentos para HIVIAIDS no contexto do Acordo Trips. Nossa hipótese é que, entre Brasil e México, o país que permitiu patamares

(2) WORLD BANK. World Bank warning: AIDS to cause complete economic collapse within 3 generations. South African Medical Journal, v. 93, n. 10, p. 745-746, 2003.

(3) COHEN-KOHLER, Jillian Clare; FORMAN, Lisa; LIPKUS, Nathaniel. Addressing legal and political barriers to global pharmaceutical access: options for remedying the impact of the Agreement on Trade-Related Aspects of Intellectual Property Rights (Trips) and the imposition of TRIP-plus standards. Health Economics, Policy and Law, v. 3, n. 3, p. 231, jul. 2008.

(4) SATYANARAYANA, K. Trips, patents \& HIVIAIDS drugs. Indian J Med Res, v. 121, n. 4, p. 211$214,2005$. 
mais altos de propriedade industrial no contexto do Acordo Trips (México) sofreu mais em termos de saúde pública, no que tange ao bem-estar da população e especialmente ao custo econômico do tratamento, do que aquele que fez uso das flexibilidades e salvaguardas (Tabela 1) do mesmo acordo para a defesa do interesse público (Brasil). A escolha de Brasil e México neste estudo deve-se ao fato de estes dois países representarem economias importantes da América Latina e também ao fato de que a prevalência absoluta de HIVIAIDS tem sido a mais alta nestes dois países do continente.

\begin{tabular}{|c|c|}
\hline FLEXIBILIDADES & DEFINIÇÃO \\
\hline $\begin{array}{l}\text { PERÍODOS DE TRANSIÇÃO } \\
\text { para patentes farmacêuticas. } \\
\text { Artigos } 65,66 \text { do Acordo } \\
\text { Trips e parágrafo } 7 \text { da } \\
\text { Declaração de Doha }\end{array}$ & $\begin{array}{l}10 \text { anos (até 2005) para países em } \\
\text { desenvolvimento e } 20 \text { anos (até 2016) para países } \\
\text { menos desenvolvidos, que não outorgavam } \\
\text { patentes para produtos e processos farmacêuticos } \\
\text { antes de janeiro de } 1995 \text {. }\end{array}$ \\
\hline $\begin{array}{l}\text { LICENÇA COMPULSÓRIA } \\
\text { Prevista no artigo } 31 \text { do } \\
\text { Acordo Trips }\end{array}$ & $\begin{array}{l}\text { Quando autoridades licenciam companhias ou } \\
\text { indivíduos que não são os titulares da patente, para } \\
\text { fabricar, usar, vender ou importar um produto sob } \\
\text { proteção patentária, sem a autorização do detentor } \\
\text { da patente. }\end{array}$ \\
\hline $\begin{array}{l}\text { IMPORTAÇÃO PARALELA } \\
\text { Prevista no artigo } 6^{\circ} \text { do } \\
\text { Acordo Trips }\end{array}$ & $\begin{array}{l}\text { Quando um produto fabricado legalmente } \\
\text { no exterior é importado por outro país sem a } \\
\text { autorização do titular dos direitos de propriedade } \\
\text { intelectual. O princípio legal no caso é a } \\
\text { "exaustão", ou seja, a ideia de que, quando o } \\
\text { detentor da patente vende um lote de seu produto } \\
\text { no mercado, seus direitos patentários estão } \\
\text { exauridos naquele lote. }\end{array}$ \\
\hline $\begin{array}{l}\text { PROVISÃO ou EXCEÇÃO } \\
\text { BOLAR } \\
\text { Prevista no artigo } 30 \text { do } \\
\text { Acordo Trips }\end{array}$ & $\begin{array}{l}\text { Permite que fabricantes de medicamentos } \\
\text { genéricos possam utilizar uma invenção } \\
\text { patenteada para obter permissão para } \\
\text { comercialização - de autoridades de saúde, por } \\
\text { exemplo - sem a permissão do titular da patente e } \\
\text { antes que a proteção patentária expire. }\end{array}$ \\
\hline $\begin{array}{l}\text { USO EXPERIMENTAL } \\
\text { Previsto no artigo } 30 \text { do } \\
\text { Acordo Trips }\end{array}$ & $\begin{array}{l}\text { Permite que pesquisadores possam utilizar } \\
\text { invenções patenteadas em suas pesquisas, com o } \\
\text { objetivo de entender melhor a invenção. }\end{array}$ \\
\hline $\begin{array}{l}\text { ATUAÇÃO DO SETOR } \\
\text { DE SAÚDE na análise } \\
\text { de pedidos de patentes. } \\
\text { Implícita no artigo } 8 \text { do } \\
\text { Acordo Trips }\end{array}$ & $\begin{array}{l}\text { Refere-se à atuação de profissionais do Ministério } \\
\text { da Saúde nos processos de análise dos pedidos de } \\
\text { patentes farmacêuticas. }\end{array}$ \\
\hline
\end{tabular}




\section{MÉTODOS}

Esta é uma pesquisa de tipo descritiva usando o método comparativo e o método histórico. Os procedimentos metodológicos estão baseados na análise de fontes primárias de relatos e opiniões de profissionais de diversas instituições envolvidas na problemática em ambos os países e no exame de fontes secundárias (documentos oficiais, livros e publicações especializadas nas áreas respectivas, sites oficiais de várias instituições e diversos jornais), de modo a recolher evidências históricas e embasamentos teóricos, assim como evidências empíricas que auxiliem na análise.

\section{RESULTADOS E DISCUSÃO}

\section{ANÁLISE DA LPI DE BRASIL E MÉXICO}

\subsection{No Brasil}

É importante esclarecer que, antes de 1945, a LPI brasileira outorgava proteção de patentes para produtos e processos farmacêuticos. Naquele ano, a legislação foi modificada para excluir proteção de invenções relacionadas a: alimentos, medicamentos, matérias e substâncias obtidas por meios e processos químicos. Isso ocorreu durante o governo do presidente Vargas, visando favorecer a substituição de importações desses produtos estratégicos e o desenvolvimento de uma indústria farmacêutica nacional. ${ }^{(5)} \mathrm{Em} 1969$, uma mudança no Código de Propriedade Industrial do Brasil eliminou completamente o patenteamento no setor farmacêutico, até a atual Lei de Propriedade Industrial( ${ }^{(6)}$, ratificada em 14 de maio de 1996.

Desde a década de 1980, o Brasil é motivo de preocupação dos Estados Unidos em termos de "burla" das regras de propriedade intelectual. Segundo Tachinardi, mais do que um alvo entre outros, o Brasil era visto como uma espécie de líder dos países em desenvolvimento e possuía um mercado consumidor significativo para os produtos norte-americanos. Consequentemente,

(5) CORREA, Marilena; CASSIER, Maurice. Saúde pública, ciência e indútria: os programas industriais de cópia de medicamentos contra AIDS em laboratórios farmacêuticos brasileiros e a política de acesso universal ao tratamento. In: CORREA, Marilene; CASSIER, Maurice (Org.). AIDS e saúde pública: contribuições à reflexão sobre uma nova economia política do medicamento no Brasil. Rio de Janeiro: Ed. UERJ, 2010. p. 142.

(6) BRASIL. Lei n 9.279, de 14 de maio de 1996. "Regula direitos e obrigações relativos à propriedade industrial”. Disponível em: <http://www.planalto.gov.br/ccivil_03/Leis/L9279.htm>. Acesso em: 10 out. 2012. 
o tratamento dispensado pelos Estados Unidos ao Brasil deveria ser ainda mais duro do que em relação às demais nações. ${ }^{(7)}$ Uma das maiores provas do empenho norte-americano em tornar o Brasil um exemplo ocorreu durante o conflito em torno das patentes farmacêuticas na década de 1980 . O contencioso iniciou-se em decorrência da pressão norte-americana para a alteração da antiga LPI brasileira (Lei $n^{\circ} 5.772^{(8)}$, de 1971). Ela entrava em choque com a estratégia norte-americana de endurecimento dos "princípios, normas, regras e procedimentos de tomada de decisão" relacionados à proteção da propriedade intelectual. Para atingir seus objetivos, em 1988, os Estados Unidos chegaram a aplicar sanções unilaterais contra o Brasil. No início da década de 1990, as pressões externas e o consequente medo da queda do seu prestígio internacional, por ser visto como um país associado à "pirataria", provocaram uma mudança na posição do governo brasileiro em relação à lei de patentes, resultando na reforma da LPI. Sua nova versão, aprovada em 1996, inclui todos os termos do Acordo Trips.

Segundo Loyola, logo após assumir o governo, em 1990, o presidente Fernando Collor promoveu uma ampla e praticamente irrestrita abertura da economia. A importação de forma indiscriminada teve efeitos nocivos sobre o setor farmacêutico e farmacoquímico nacional. Os preços dos medicamentos, sujeitos, até então, a regimes de controle direto pelo governo federal, foram também gradualmente liberados, tornando-se inteiramente livres a partir de maio de 1992, ao que se seguiu um forte aumento dos preços praticados pela indústria. ${ }^{(9)}$

A LPI brasileira atual entrou em vigor a partir de 15 de maio de 1997 e é mais abrangente quanto à proteção das patentes. Em comparação com outros países, a LPI brasileira é tida como bastante liberal. Entre outros dispositivos, ela antecipou em 10 anos o período de transição previsto pelo Acordo Trips para a inclusão de medicamentos no rol de bens patenteáveis, do qual a Índia, por exemplo, ao contrário do Brasil, soube tirar proveito ${ }^{(10)}$.

(7) TACHINARDI, Maria Helena. (1993). A guerra das patentes: o conflito Brasil x Estados Unidos sobre propriedade intelectual. São Paulo: Paz e Terra. Apud: CEPALUNI, Gabriel. Regimes internacionais e o contencioso das patentes para medicamentos: estratégias para países em desenvolvimento. Contexto Internacional, Rio de Janeiro, v. 27, n. 1, p. 73, 2005.

(8) BRASIL. Lei $n^{\circ} .5 .772$, de 21 de dezembro de 1971. "Revogada pela Lei $n^{\circ} 9.279$, de 1996 Institui o Código da Propriedade Industrial, e dá outras providências". Disponível em: <http://www.planalto. gov.br/ccivil_03/leis/L5772impressao.htm>. Acesso em: 10 out. 2012.

(9) LOYOLA, Maria Andréa. Medicamentos e saúde pública em tempos de AIDS: metamorfoses de uma política dependente. Ciência \&. Saúde Coletiva, São Paulo, v. 13, suppl., p. 763-778, 2008. Disponível em: <http://www.scielo.br/scielo.php?pid=S1413-81232008000700027\&script=sci_ arttext>. Acesso em: 10 out. 2012.

(10) Id. Aids e saúde pública: a implantação de medicamentos genéricos no Brasil. In: CORREA, Marilene; CASSIER, Maurice (Orgs.). AIDS e saúde pública: contribuições á reflexão sobre uma nova economia política do medicamento no Brasil. Rio de Janeiro: Ed. UERJ, 2010. p. 44. 


\subsection{No México}

Ao longo de três décadas de sua vigência, a LPI mexicana de 1942 foi um instrumento aceitável para a proteção do direito dos inventores. Porém, a influência da política legislativa desenhada pelo Pacto Andino reforçou o pensamento do grupo de conselheiros economistas da administração, para quem aquela lei já se mostrava ineficaz para resolver problemas relacionados com a regulação jurídica do direito dos inventores. A filosofia do ordenamento proposto considerava que os obstáculos para o desenvolvimento derivavam do inadequado regime tradicional de propriedade industrial e que o sistema de patentes nos países pobres tinha sido um instrumento para perpetuar situações de injustiça e subordinação, criando um colonialismo econômico e tecnológico. Para pôr fim a tal situação e atingir as metas assinaladas de liberdade, foi proposto que fossem excluídas como objeto de patentes as invenções relacionadas à saúde e alimentação da população, incluindo a produção agrícola, a defesa do meio ambiente e a energia nuclear. E para estimular e fomentar a atividade inventiva e divulgar as invenções, incluindo medicamentos, promulgou-se a Ley de Invenciones y Marcas $^{(11)}$ de 1976, vigente até 1991, em que a única proteção disponível para medicamentos consistia na obtenção dos denominados "certificados de invención"(12).

A partir de 1991, com a promulgação da Ley de Fomento y Protección de La Propiedad Industrial(13), o México adotou uma legislação totalmente orientada à proteção plena dos direitos de propriedade industrial, com especial ênfase nas patentes. A mudança de rumo se deu num amplo marco de ajustes legais em matéria de propriedade intelectual, que o país adotou, e ainda numa profunda reorientação em todo aparato normativo de cunho econômico. Em relação às patentes, algumas das novidades mais destacadas consistiram na concessão de patenteamento a invenções que tradicionalmente tinham sido excluídas, como é o caso das invenções biotecnológicas e, claro, os processos e produtos farmacêuticos, assim como a proteção para novas variedades vegetais. Adicionalmente, a vigência de patentes se incrementou de maneira sensível, passando de 14 anos (reforma de 1987) para 20 anos a partir da data de apresentação.

Para compreender melhor as condições em que a nova proteção outorgada em matéria de patentes foi gestada, é necessário lembrar que o México tinha iniciado, desde sua inserção no então Acordo Geral de Tarifas e Comércio, de 1987 (GATT), uma série de medidas orientadas a sua participação em

(11) MEXICO. Ley de Invenciones y Marcas. Disponível em: <http://biblio.juridicas.unam.mx/ libros/1/423/13.pdf. >. Acesso em: 10 out. 2012.

(12) RANGEL, David. Derecho de la propiedad industrial e intelectual. México: Universidad Nacional Autónoma de México, 1992. p 35.

(13) JUSTIA MEXICO. Ley de la Propiedad Industrial. Disponível em: <http://mexico.justia.com/ federales/leyes/ley-de-la-propiedad-industrial/gdoc/>. Acesso em: 10 out. 2012. 
esquemas de globalização econômica. Em 1990, a opção de levar adiante um tratado de livre comércio com Canadá e Estados Unidos se apresentava como um dos principais projetos do governo do presidente Salinas de Gortari. Nesse contexto, segundo Jalife, o México respondeu com a nova legislação de propriedade industrial a algumas das queixas mais insistentes dos países desenvolvidos, derivadas da baixa proteção de direitos nesse campo. Depois, aderiu ao Trips e passou de um sistema que somente admitia proteção aos procedimentos de produção de produtos farmacêuticos para outro sistema que, adequando-se à nova norma internacional, amplia a proteção a todos os campos da tecnologia. ${ }^{(14)}$

Assim, até a década de 1990, nem Brasil nem México (nem muitos outros países em desenvolvimento, tanto quanto desenvolvidos como Japão e Itália, até 1970) outorgavam patentes sobre produtos farmacêuticos. Companhias locais podiam produzir versões genéricas de drogas novas patenteadas na Organização para Cooperação e Desenvolvimento Econômico (OCDE). Somente nos anos 1990 ambos os países introduziram patentes a fármacos para cumprir com as novas obrigações internacionais.

Numa análise recente, Shadlen compara alguns aspectos de políticas de saúde e propriedade industrial que tiveram que ser contemplados pelos países assinantes do Acordo Trips e do Nafta (Tabela 2).

Por outro lado, na Tabela 3, apresentamos as principais caraterísticas das LPI brasileira e mexicana implementadas nos anos 1990, mostrando que, na sua origem, tinham parâmetros de proteção de propriedade industrial muito similares. Para Shadlen, ambos os países excederam bastante suas novas obrigações, facilitando o patenteamento para uma ampla variedade de produtos farmacêuticos e farmacoquímicos, e dando aos proprietários amplos e prolongados direitos de exclusão. Também para algumas ONGs (como a Oxfam), do ponto de vista da saúde pública, os regimes de patentes de ambos os países foram preocupantes. ${ }^{(15)}$ Por exemplo, ofereceram patentes pipeline, não permitiram importações paralelas, apresentaram mecanismos rudimentares para licenças compulsórias no âmbito dos problemas de saúde e, nem Brasil (inicialmente) nem México, incorporaram o mecanismo de "provisão bolar".

(14) JALIFE, Mauricio. Análisis de aspectos legales y comerciales de las patentes de medicamentos en México. Biblioteca Jurídica Virtual del Instituto de Investigaciones Jurídicas de la UNAM. Disponível em: <http://biblio.juridicas.unam.mx/libros/6/2634/6.pdf>. Acesso em: 10 out. 2012.

(15) OXFAM. Patentes contra pacientes: cinco años después de la Declaración de Doha. Disponível em: <http://www.slideshare.net/guest292ba1/patentes-vs-pacientes-2951185>. Acesso em: 10 out. 2012. 
Tabela 2 - Propriedade industrial e política de saúde: Trips (OMC) vs. Nafta

\begin{tabular}{lcc|}
\hline Aspecto da política & Trips (OMC) & Nafta \\
\hline Patentes farmacêuticas & Requeridas & Idem \\
Patentes pipeline & Não requeridas & Requeridas \\
Licença compulsória & Permitida; descrição ampla & Idem \\
Importações paralelas & Permitidas & Não permitidas \\
Provisão bolar & Permitida & Idem \\
$\begin{array}{l}\text { Procedimento de registro } \\
\text { de droga: linkage }\end{array}$ & Não discutido & Idem \\
\hline
\end{tabular}

Fonte: SHADLEN, Kenneth ${ }^{(16)}$

\begin{tabular}{|c|c|c|}
\hline Caraterísticas da LPI & Brasil & México \\
\hline Patentes farmacêuticas & $\operatorname{Sim}(1996)$ & $\operatorname{Sim}(1991)$ \\
\hline Patentes pipeline & $\begin{array}{c}\text { Sim (1996), arts. } 230 \text { e } \\
231\end{array}$ & $\begin{array}{l}\text { Sim (1991), Art. } 12 \\
\text { transitório }\end{array}$ \\
\hline Licença compulsória & Sim, arts. $68,70,71$ e 72 & Sim, Art. 77 \\
\hline Importações paralelas & Não & Não \\
\hline Provisão bolar & Não & Não \\
\hline $\begin{array}{l}\text { Procedimento de registro } \\
\text { de droga: linkage }\end{array}$ & Não & Não \\
\hline
\end{tabular}

Como resultado desses regimes "Trips-PLUS", mais drogas foram patenteadas em ambos os países e tornou-se mais difícil contar com a competição de genéricos para reduzir os preços. ${ }^{(17)}$

Com base nas Tabelas 2 e 3, podemos ver que tanto o Brasil como o México modificaram sua LPI para implementar as normas do Acordo Trips. No caso

(16) SHADLEN, Kenneth. The politics of patents and drugs in Brazil and Mexico: the industrial bases of health policies. Comparative Politics, New York, v. 42, n. 1, p. 41-58, 2009. Disponível em: <http:// eprints.Ise.ac.uk/27051/>. Acesso em: 10 out. 2012.

(17) BERNARDO, Pedro \& ROMANO, Ricardo. Padrões de regulação de preços do mercado de medicamentos: experiência brasileira dos anos 90 e novos arranjos institucionais. Em: NEGRI e DE GIOVANNI, Geraldo (org). Brasil: radiografia da saúde. Campinas, Unicamp, 2001. Apud: LOYOLA, Maria Andréa. Aids e saúde pública: a implantação de medicamentos genéricos no Brasil, cit., p. 40. 
do México, essa mudança aconteceu antes, em 1991, como preparação para a assinatura do Nafta, acordo que tem um capítulo sobre propriedade intelectual. $\mathrm{Na}$ LPI mexicana não constam algumas flexibilidades do Acordo Trips, como a "exaustão nacional" ou a "exceção bolar", estando dessa maneira numa condição de menor proteção para a saúde pública, em comparação ao Brasil. Ao final dos anos 1990, os dois países divergiram em suas políticas (Tabela 4). No caso da LPI brasileira, já aparecem, dentro das flexibilidades e salvaguardas contempladas, a licença compulsória, a importação paralela em caso de exaustão nacional e a provisão bolar, incorporadas num segundo momento e que discutiremos a seguir.

\begin{tabular}{|c|c|c|}
\hline Provisões e mecanismos & Brasil & México \\
\hline $\begin{array}{l}\text { PERÍODO DE TRANSIÇÃO (até 2005) } \\
\text { para outorgar patentes para produtos e } \\
\text { processos farmacêuticos }\end{array}$ & Brasil usou um ano & Não utilizado \\
\hline MATÉRIA PATENTEÁVEL & $\begin{array}{l}\text { Produtos ou processos } \\
\text { novos ou que } \\
\text { incorporaram um novo } \\
\text { passo e poderiam ter } \\
\text { aplicação industrial }\end{array}$ & Idem \\
\hline $\begin{array}{l}\text { TERMO DE PROTEÇÃO (limite de } \\
\text { tempo para a proteção da patente) }\end{array}$ & $\begin{array}{c}20 \text { anos como tempo } \\
\text { limite }\end{array}$ & Idem \\
\hline $\begin{array}{l}\text { CARGA DA PROVA (se uma pessoa é } \\
\text { suspeita de ter infringido uma patente, } \\
\text { ela deveria provar sua inocência) }\end{array}$ & $\begin{array}{l}\text { Reversão da carga da } \\
\text { prova }\end{array}$ & \\
\hline \multirow[t]{3}{*}{ FLEXIBILIDADES E SALVAGUARDAS } & $\begin{array}{l}\text { Importação paralela / } \\
\text { Exaustão nacional }\end{array}$ & Não \\
\hline & Licença compulsória & $\begin{array}{l}\text { Licença } \\
\text { compulsória }\end{array}$ \\
\hline & Provisão bolar & Não \\
\hline
\end{tabular}

Fonte: OLIVEIRA, M. A.; BERMUDEZ, J.A.Z.; CHAVES, G. C. et al ${ }^{(18)}$

(18) OLIVEIRA, Maria; BERMUDEZ, Jorge; CHAVES, Gabriela; VELASQUES, German. Has the implementation of the Trips agreement in Latin America and the Caribbean produced intellectual property legislation that favors public health? Bulletin of the World Health Organization, v. 82, n. 11, p. 815-821, Nov. 2004; CHAVES, Gabriela; OLIVEIRA, Maria. A proposal for measuring the degree of public health - sensitivity of patent legislation in the context of the WTO Trips Agreement. Bulletin of the World Health Organization, v. 85, n. 1, p. 49-56, Jan. 2007. 


\section{LICENÇA COMPULSÓRIA}

\subsection{No Brasil}

A licença compulsória foi incorporada pela legislação brasileira e pode ser concedida sob diversos fundamentos (Tabela 5).

\begin{tabular}{|c|c|c|}
\hline Bases para emissão de licença compulsória & Brasil & México \\
\hline $\begin{array}{l}\text { Falha na exploração da patente (o produto ou processo } \\
\text { patenteado está fora do mercado há três anos) }\end{array}$ & Sim & $\operatorname{Sim}$ \\
\hline Interesse público (ex.: proteger a saúde pública) & Sim & $\operatorname{Sim}$ \\
\hline Emergência nacional & Sim & Sim \\
\hline $\begin{array}{l}\text { Providência contra práticas anticompetitivas e } \\
\text { competência desleal }\end{array}$ & Sim & Não \\
\hline $\begin{array}{l}\text { Dificuldades para obter licença sob termos razoáveis } \\
\text { (quando negociadores e o detentor da patente chegam a } \\
\text { um impasse) }\end{array}$ & Não & Não \\
\hline Falha do detentor da patente em produzir localmente & Sim & Não \\
\hline $\begin{array}{l}\text { Patentes dependentes (quando uma patente não pode } \\
\text { ser explorada sem usar outra patente) }\end{array}$ & Sim & Não \\
\hline
\end{tabular}

Fonte: OLIVEIRA, M. A.; BERMUDEZ, J. A. Z.; CHAVES, G. C. et al. ${ }^{(19)}$

Dessa maneira, o Art. 68 da legislação brasileira de patentes prevê que o "titular ficará sujeito a ter a patente licenciada compulsoriamente se exercer os direitos dela decorrentes de forma abusiva ou por meio dela praticar abuso de poder econômico". O mesmo dispositivo estabelece ainda que uma licença compulsória possa ser também concedida em caso de não exploração do objeto da patente no território brasileiro ou quando a comercialização do produto patenteado não satisfizer as necessidades do mercado ${ }^{(20)}$. Poderá haver licenciamento compulsório ainda em casos de patentes dependentes, nos termos

(19) OLIVEIRA, Maria; BERMUDEZ, Jorge; CHAVES, Gabriela; VELASQUES, German. op. cit., p. 815-821.

(20) Art. 68 (...) $\S 1^{\circ}$ Ensejam, igualmente, licença compulsória: I - a não exploração do objeto da patente no território brasileiro por falta de fabricação ou fabricação incompleta do produto, ou, ainda, a falta de uso integral do processo patenteado, ressalvados os casos de inviabilidade econômica, quando será admitida a importação; ou II - a comercialização que não satisfizer às necessidades do mercado (...). 
previstos no Art. 70(21) da LPI. Por fim, o Art. 71 prevê que poderá ser concedida uma licença compulsória em "casos de emergência nacional ou interesse público declarados em ato do Poder Executivo Federal". Ainda com essas flexibilidades estabelecidas em lei, na prática isso só veio a se materializar em 2007.

A possibilidade de fornecimento de licenças compulsórias só começou a chamar a atenção dos norte-americanos após a criação do programa brasileiro de combate ao HIV/AIDS. Em 1997, o Brasil tornou obrigatória a distribuição de medicamentos ARVs aos portadores dessa doença. Para escapar ao monopólio de patentes e diminuir o custo do programa, o Ministério da Saúde, por intermédio da Rede de Laboratórios Farmacêuticos Oficiais, passou a produzir substitutos genéricos desses medicamentos, sendo de fundamental importância a Lei dos Genéricos (Lei ${ }^{\circ} 9.787^{(22)}$ ) para a produção local dessas drogas. Tudo isso chamou a atenção do governo norte-americano, que voltou a pressionar o Brasil(23). Em 2000, os Estados Unidos questionaram os arts. 68 e 71 da Lei 9.279, que previam a possibilidade do uso de licenciamento compulsório em casos de emergência da saúde pública, sugerindo que não estavam de acordo com o Trips. O Brasil foi inserido na Section 301 Watch List, acusado de ser "desrespeitador de patentes" (patent-miscreant). Em 30 de maio de 2000, os Estados Unidos entraram com pedido de consultas junto ao governo brasileiro na OMC. Não satisfeitos com a resposta brasileira, segundo Oliveira, em 9 de janeiro de 2001, entraram com pedido de estabelecimento de pane/no Órgão de Solução de Controvérsias da OMC, apresentando a mesma queixa e afirmando que as consultas não trouxeram os resultados esperados, nem tampouco a solução para o conflito. ${ }^{(24)}$

Segundo Mónica de Guise, os Estados Unidos argumentavam que o referido Art. 68 estabelecia uma discriminação contra titulares estadunidenses de patentes brasileiras cujos produtos eram importados, mas não produzidos

(21) Art. 70. A licença compulsória será ainda concedida quando, cumulativamente, se verificarem as seguintes hipóteses: I - ficar caracterizada situação de dependência de uma patente em relação a outra; II - o objeto da patente dependente constituir substancial progresso técnico em relação à patente anterior; e III - o titular não realizar acordo com o titular da patente dependente para exploração da patente anterior. $\S 1^{\circ}$ Para os fins deste artigo considera-se patente dependente aquela cuja exploração depende obrigatoriamente da utilização do objeto de patente anterior. $\S 2^{\circ}$ Para efeito deste artigo, uma patente de processo poderá ser considerada dependente de patente do produto respectivo, bem como uma patente de produto poderá ser dependente de patente de processo. $\S 3^{\circ} \mathrm{O}$ titular da patente licenciada na forma deste artigo terá direito a licença compulsória cruzada da patente dependente.

(22) BRASIL. Lei n 9.787, de 10 de fevereiro de 1999. "Altera a Lei no 6.360, de 23 de setembro de 1976, que dispõe sobre a vigilância sanitária, estabelece o medicamento genérico, dispõe sobre a utilização de nomes genéricos em produtos farmacêuticos e dá outras providências." Disponível em: <http://www.planalto.gov.br/ccivil_03/leis/l9787.htm>. Acesso em: 10 out. 2012.

(23) CEPALUNI, Gabriel. op. cit., p. 79.

(24) OLIVEIRA, Marcelo de. Multilateralismo, democracia e política externa no Brasil: contenciosos das patentes e do algodão na Organização Mundial de Comércio. Contexto Internacional, Rio de Janeiro, v. 29, n. 1, p. 17, 2007. 
no Brasil. Para os Estados Unidos, essa legislação fazia parte de uma política industrial que conflitava com o disposto no Art. 27.1 ${ }^{(25)}$ do Trips. O Brasil respondeu que suas leis não eram discriminatórias e, na realidade, continham disposições paralelas à legislação de patentes dos Estados Unidos, especialmente no que tange ao requisito de exploração local. Segundo o Brasil, o Art. $204^{(26)}$ da lei norte-americana exigia que as empresas pequenas e as universidades que recebessem financiamento do governo federal "fabricassem suas invenções dentro dos Estados Unidos". Ademais, o Art. 209(27) da mesma lei estabelecia o requisito de exploração local para patentes de propriedade federal. O Brasil pediu que fossem realizadas consultas sobre a compatibilidade das normas estadunidenses em questão com o Acordo Trips. ${ }^{(28)}$

A importância da licença compulsória foi ilustrada naquela época, quando foi utilizada como instrumento de pressão de negociação de preços de quatro medicamentos ARVs. No processo de negociação de preços - que envolveu o governo brasileiro e três laboratórios transnacionais (Merck \& Co, Roche e Abbott) -, o Instituto de Tecnologia em Fármacos (Farmanguinhos/Fundação Oswaldo Cruz/Ministério da Saúde) forneceu ao Ministério da Saúde a referência para o estabelecimento do preço aceitável, assim como sua capacidade de desenvolver engenharia reversa, habilitando o governo a ameaçar com a emissão de licença compulsória no caso do impasse. O resultado principal dessa negociação, para Bermudez et al., foi uma redução considerável dos preços, da ordem de 64,8\%, para Indinavir; 59\% para Efavirenz; 40\% para Nefilnavir e $46 \%$ para Lopinavir/r, permitindo a sustentabilidade do programa nacional de acesso universal à terapia $A R V .^{(29)}$

No mês de maio, na Assembleia anual da ONU, reunindo 191 países, o Brasil iniciava campanha pedindo aos membros da instituição que desistissem

(25) Artigo 27 - Matéria Patenteável - 1. Sem prejuízo do disposto nos parágrafos 2 e 3 abaixo, qualquer invenção, de produto ou de processo, em todos os setores tecnológicos, será patenteável, desde que seja nova, envolva um passo inventivo e seja passível de aplicação industrial5. Sem prejuízo do disposto no parágrafo 4 do Artigo 65, no parágrafo 8 do Artigo 70 e no parágrafo 3 deste Artigo, as patentes serão disponíveis e os direitos patentários serão usufruíveis sem discriminação quanto ao local de invenção, quanto a seu setor tecnológico e quanto ao fato de os bens serem importados ou produzidos localmente. ACORDO Trips ou Acordo Adpic (1994). Disponível em: $<$ http://www.cultura.gov.br/site/wp-content/uploads/2008/02/ac_trips.pdf>. Acesso em: 10 out. 2012.

(26) U.S. Patent Act, 35 USC. Disponível em: <http://www.bitlaw.com/source/35usc/index.html>. Acesso em: 10 out. 2012.

(27) U.S. Patent Act, 35 USC. Disponível em: <http://www.bitlaw.com/source/35usc/index.html>. Acesso em: 10 out. 2012.

(28) GUISE, Mônica. O requisito de exploração local do objeto da patente: uma análise da legislação no contexto internacional. In: CARVALHO, Patrícia (Org.). Propriedade intelectual: estudos em homenagem à professora Maristela Basso. Curitiba: Juruá, 2005. p 171.

(29) BERMUDEZ, Jorge; OLIVEIRA, Maria Auxiliadora; CHAVES, Gabriela. O Acordo Trips da OMC e os desafios para a saúde pública. In: BERMUDEZ, Jorge; OLIVEIRA, Maria Auxiliadora; ESHER, Ângela (Coords.). Acesso a medicamentos: direito fundamental, papel do Estado. Rio de Janeiro: ENSP, 2004. p. 76. 
de ações que obstruíssem os esforços de outros países para expandir o acesso e a produção local de ARVs genéricos. A proposta brasileira, que incluía também a criação de um fundo global para a compra de remédios, foi "bombardeada" pelos Estados Unidos e pela União Europeia(30). No dia 5 de julho de 2001, as partes notificaram ao Órgão de Solução de Controvérsias da OMC que haviam chegado a um acordo satisfatório: os Estados Unidos retiravam sua reclamação contra o Brasil e o Brasil concordava que, caso considerasse necessário aplicar o Art. 68 para a concessão de uma licença compulsória contra patentes de empresas estadunidenses, celebraria conversações prévias sobre o assunto com os Estados Unidos. Os Estados Unidos indicaram que esperavam que o Brasil não insistisse em impugnar sua legislação(31).

Posteriormente, em 2005, outro evento seria de grande importância. Segundo Chaves et al., os gastos com a compra do medicamento Kaletra ${ }^{\circledR}$ (associação dos princípios ativos Lopinavir e Ritonavir), produzido pelo Laboratório Abbott, representavam naquele ano aproximadamente $30 \%$ de todo o gasto do Programa Nacional DST/AIDS com a compra de medicamentos. Esse valor levou o governo brasileiro a entrar em um processo de negociação com a Abbott, visando à redução do preço do medicamento. Depois de frustradas tentativas de negociação, o então ministro da Saúde do Brasil declarou, em junho de 2005, como sendo de interesse público a fabricação do Kaletra ${ }^{\circledR}$. Essa declaração foi o primeiro passo para a concessão de uma licença compulsória por interesse público, já que possibilitaria a produção nacional do referido medicamento, com custo menor e transferência de tecnologia. No entanto, ao mesmo tempo em que declarou o interesse público do Kaletra ${ }^{\circledR}$, o governo brasileiro concedeu um prazo adicional para que o Laboratório Abbott oferecesse uma diminuição do valor cobrado pelo medicamento, o que evitaria a adoção do licenciamento compulsório. Assim, em outubro de 2005, foi firmado um contrato entre o governo brasileiro e o Laboratório Abbott para o fornecimento do medicamento. O acordo, apesar de representar uma redução no preço cobrado pelo medicamento, previu cláusulas contrárias ao interesse público nacional, tais como: obrigatoriedade de não concessão de licença compulsória, não fornecimento de qualquer assistência de fabricação do medicamento e manutenção do preço estipulado até o final de 2011, quando a patente do medicamento já estaria próxima de expirar ${ }^{(32)}$. A adoção da licença compulsória tem sido apoiada pela sociedade civil brasileira nos últimos anos como uma forma de superar ameaças à sustentabilidade do acesso universal a tratamento impostas pelos altos custos dos medicamentos.

(30) LOYOLA, Maria; VILELA, Pedro; GUIMARÂES, Eduardo. Medicamentos e patentes na ordem do dia: a mídia e "a guerra de patentes". In: CORREA, Marilene; CASSIER, Maurice (Orgs.). AIDS e saúde pública: contribuições à reflexão sobre uma nova economia política do medicamento no Brasil. Rio de Janeiro: Ed. UERJ, 2010. p. 83.

(31) GUISE, Mônica. op. cit.

(32) CHAVES, Gabriela; FOGAÇA, Marcela; REIS, Renata. Acesso a medicamentos e propriedade intelectual no Brasil: reflexões e estratégias da sociedade civil. Revista Internacional de Direitos Humanos, São Paulo, v. 5, n. 8, p. 180, 2008. 
No entanto, essa medida só foi utilizada no Brasil em 2007, para o medicamento Efavirenz. O custo por paciente/ano, com esse medicamento, no Brasil era de 580 dólares desde 2003 , enquanto no mercado internacional era possível encontrar preços duas vezes menores. Após longa tentativa de negociação com a Merck, a única oferta realizada pela empresa foi a de reduzir os preços em $2 \%$. O Efavirenz foi declarado de interesse público em abril e a licença compulsória foi emitida em maio de $2007^{(33)}$.

Importante aqui destacar que o uso da licença compulsória no setor farmacêutico não era uma prática estranha para os países desenvolvidos. Nas décadas de 1960 e 1970, o Exército dos Estados Unidos produziu e utilizou tetraciclina e meprobamato sem a autorização dos detentores das respectivas patentes. Durante a década de 1980, foi concedida uma licença compulsória para a insulina, produzida pela empresa Eli Lilly, sob o argumento de que a empresa estava envolvida em uma conspiração com outros fabricantes do produto. Ainda nos Estados Unidos, durante a década de 1990, várias licenças compulsórias para medicamentos foram concedidas com o intuito de minimizar o monopólio decorrente de fusões de empresas que dominavam o mercado de uma mesma classe terapêutica. Em 2001, os Estados Unidos utilizaram a licença compulsória como instrumento para pressionar a redução de preços de medicamentos. Em decorrência dos ataques por antraz, o país se deparou com uma potencial ameaça de ataque bioterrorista e imediatamente considerou a possibilidade de emissão de licença compulsória para o medicamento ciprofloxacino(34).

Dessa maneira, no Brasil, o licenciamento compulsório revelou um compromisso governamental com a sustentabilidade do acesso ao tratamento de HIV/ AIDS, em um cenário em que os medicamentos sujeitos à proteção patentária apresentavam preços exorbitantes e inacessíveis para a grande maioria dos países em desenvolvimento. Além disso, a possibilidade sinalizada pelo governo brasileiro de fazer uso da licença compulsória para outros medicamentos é extremamente positiva, pois visa assegurar a sustentabilidade não apenas do Programa Nacional DST/AIDS, mas também de todo o sistema público de saúde. Nesse sentido, na mais recente Assembleia da ONU, que elevou as doenças crônicas não transmissíveis à condição de prioridade para as políticas públicas dos Estados, a presidente Dilma Rousseff defendeu quebra de patentes de drogas usadas contra câncer, diabetes, doenças cardiovascualres e pulmonares $^{(35)}$, desencadeando uma imediata reação das empresas farmacêuticas ${ }^{(36)}$.

(33) CHAVES, Gabriela; FOGAÇA, Marcela; REIS, Renata. op. cit., p. 181.

(34) CHAVES, Gabriela. Patentes farmacêuticas: por que dificultam o acesso a medicamentos? Rio de Janeiro: Associação Brasileira Interdisciplinar de AIDS, 2006..

(35) FORNETTI, Verena; FAGUNDES Alvaro. (Faltou a virgula depois de FORNETTIi)

(36) FORMENTI, Ligia. Farmacêuticas reagem a discurso de Dilma. O Estado de S. Paulo, São Paulo, 21 set. 2011. A18. 


\subsection{No México}

No caso do México, as licenças compulsórias obedecem a considerações relacionadas à falta de exploração da invenção por parte do titular, mas não a aspectos de estabilização do mercado ou de preços. Em relação às licenças previstas no Art. 77 da LPI mexicana, elas devem ser consideradas como "licenças de utilidade pública", adotadas somente em situações de emergência ou segurança pública ${ }^{(37)}$.

Também podemos observar, na Tabela 5, que o México, diferente do Brasil, não reconhece certas condições para a emissão de licença compulsória - como as práticas anticompetitivas ou concorrência desleal, a falha do detentor da patente em produzir localmente e as patentes dependentes. Esta última condição é preocupante, já que isso pode invalidar uma licença compulsória se o produto licenciado depende da produção de um produto patenteado.

Devido às consequências das elevações dos preços dos medicamentos nos anos após a entrada em vigor do Nafta e do Trips, algumas iniciativas de reforma de patentes orientadas à saúde partiram, antes que do governo, do próprio setor farmacêutico local, que emergiu nos anos 1990 como resposta à crise econômica e à cobertura limitada do Instituto Mexicano del Seguro Social I Instituto de Seguridad y Servicios Sociales de los Trabajadores del Estado (IMSS/ISSSTE). Em dezembro de 2002, membros do Partido Verde na Câmara dos Deputados apresentaram uma iniciativa que violaria as exigências Trips e Nafta (proposta de alteração do prazo de 20 para 10 anos no limite de término da patente, em casos críticos de saúde pública). Em lugar de ser rejeitada, a proposta foi modificada pela Comissão de Ciência e Tecnologia (CCyT, sigla em espanhol). Enquanto a proposta original focava no término da patente (Art. 23), a declaração revisada focou sobre a licença compulsória (Art. 77), um terreno em que o México tinha muita discrição. Em março de 2003, a CCyT aprovou uma modesta reforma que fortalecia a capacidade do Ministério da Saúde de emitir uma licença compulsória no caso de emergências de saúde. Basicamente, seria necessária apenas a emissão de uma declaração de "doença séria" pelo Ministério, por meio de um processo simplificado, para assegurar uma rápida emissão da licença compulsória. A declaração de março de 2003, similar em muitos aspectos à reforma da licença compulsória do Brasil, de 1999, levou a uma forte reação da indústria farmacêutica transnacional e de seus representantes locais. Membros do governo e legisladores foram questionados através de cartas, faxes, e-mails, ligações telefônicas e visitas pessoais do pessoal da Asociación Mexicana de Indústrias de Investigación Farmacéutica (AMIIF), de escritórios de advocacia, do United States Trade Representative (USTR) e de embaixadas estrangeiras (por exemplo, dos Estados Unidos e da Suíça).

(37) JALIFE, Mauricio. op. cit. 
O setor transnacional não somente reagiu defensiva, mas ofensivamente, convertendo as ameaças em uma oportunidade. A AMIIF tentou acabar com o projeto de reforma da lei de patentes; porém, uma vez que foi mantido vivo pela CCyT, a AMIIF e seus aliados se mobilizaram para segurar a reforma. Como resultado, a outorga de licença compulsória ficou ainda menos exequível do que sob a lei de 1991. O governo Fox, que nunca havia se interessado pela reforma da lei de propriedade industrial, juntou-se à contraofensiva transnacional. $\mathrm{O}$ coordenador legislativo da Secretaria de Governo insistiu em que a versão de março de 2003 não poderia ser aprovada e entregou à CCyT um texto revisado. Essa nova versão, aprovada pela Câmara dos Deputados, foi assinada como lei pelo presidente Fox em 2 de agosto de 2004. Este Art. 77 reformado incrementa os obstáculos para emitir licenças compulsórias, fazendo com que o processo pelo qual é declarada uma "doença séria" seja mais complicado, acabando com a possibilidade de esse argumento servir de base para uma licença compulsória e exigindo taxas mínimas de royalties extremamente altas ${ }^{(38)}$. Dessa maneira, no México, diferentemente do Brasil, não foram postas em prática as licenças compulsórias e, sem a ameaça legal de implantação destas licenças, o sucesso mexicano em reduzir os preços foi pequeno.

\section{IMPORTAÇÃO PARALELA}

\subsection{No Brasil}

No Brasil, a importação paralela foi também incorporada, porém de forma muito limitada, uma vez que sua utilização está condicionada às situações de concessão de licença compulsória por razão de abuso do poder econômico (Art. $68, \S \S 3^{\circ}$ e $4^{\circ}$, LPI). Há um projeto de lei (PL 139/99 ${ }^{(39)}$ ) tramitando no Congresso Nacional para incorporação dessa flexibilidade de forma plena. Para as políticas de acesso a medicamentos, esta flexibilidade é extremamente importante, pois as empresas farmacêuticas multinacionais costumam estabelecer preços diferenciados para um mesmo medicamento em diferentes países. Assim, a existência da importação paralela nas legislações nacionais permite que um país importe um medicamento de onde ele esteja sendo comercializado por menor preço. ${ }^{(40)}$

(38) SHADLEN, Kenneth. op. cit. p. 41-58.

(39) CÂMARA DOS DEPUTADOS. Comissão de Desenvolvimento Econômico, Indústria e Comércio. Projeto de Lei $n^{\circ}$. 139/99. "Altera a Lei $n^{\circ} 9.279$, de 14 de maio de 1996, que 'regula direitos e obrigações relativos à propriedade industrial', modificando dispositivos que dispõem sobre direitos conferidos pela patente e a concessão de licença compulsória". Disponível em: <http://www.camara. gov.br/proposicoesWeb/prop_mostrarintegra;jsessionid=0728E16CFD6051C71A68866B98211877. node1 ?codteor=402071\&filename=Tramitacao-PL+139/1999 >. Acesso em: 10 out. 2012.

(40) CHAVES, Gabriela; FOGAÇA, Marcela; REIS, Renata. op. cit., p. 177. 
Segundo Basso \& Rodrigues ${ }^{(41)}$, a maioria dos especialistas defende que o Brasil adotou o princípio da "exaustão" nacional dos direitos patentários, ou seja, o ato de introdução de bens protegidos por patentes pelo titular desta ou por seu licenciado, no mercado brasileiro, será considerado legítimo para exaurir os direitos/poderes de controle do produto protegido. Na verdade, o Art. 43, inciso IV, da LPI é uma regra que se refere apenas à "exaustão" nacional. Essa regra não faz referência à exaustão internacional, podendo, portanto, ser entendida tanto como uma regra máxima quanto mínima. Isto é, a "exaustão" é gerada, pelo menos pela comercialização em âmbito doméstico, ou apenas pela comercialização em âmbito doméstico, ficando a critério da justiça brasileira o estabelecimento dos limites à "exaustão" internacional, sendo possível fixá-la em consonância com as necessidades brasileiras de maior concorrência de produtos $^{(42)}$. Uma interpretação restritiva dos dispositivos da LPI que disciplinam a importação paralela é legalmente equivocada e reflete uma perspectiva da propriedade intelectual isolada de seus objetivos e de outras normas legais de hierarquia superior, notadamente, a Constituição Federal do Brasil de 1988. A interpretação exigida pela Carta Magna, que, por sua vez, vai ao encontro da proteção do direito à saúde no Brasil, é a da adoção pelas cortes brasileiras do princípio da "exaustão" internacional: a introdução de produto objeto de patente em qualquer lugar do mundo, desde que tenha sido feita pelo titular da patente ou com o seu consentimento, deve ser considerada ato suficiente para exaurir os direitos do titular da patente, não podendo, pois, o titular da patente interferir em atos comerciais posteriores envolvendo o produto, isto é, a exportação(43).

\subsection{No México}

O mecanismo da importação paralela está ausente na legislação mexicana, como observado na Tabela 5. Porém, na interpretação de Mauricio Jalife, catedrático da Universidad Nacional Autónoma de México (UNAM), as importações paralelas no México foram uma das novidades da Ley de Fomento y Protección de la Propriedad Industrial promulgada em 1991 e considerada como a mais importante exceção aos efeitos das patentes. Apesar das ambiguidades em que incorre, a LPI mexicana tem considerado, em geral, que a "exaustão" que se aplica é local, isto é, que não está autorizada a importação de produtos

(41) BASSO, Maristela; RODRIGUES, Edson. Avaliação legal. In: ROSSI, Francisco (Org.). Avaliação técnica, econômica e legal de capacidade de produção de antirretrovirais no Brasil. Brasília-DF: PNUD, 2008. p. 53.

(42) BASSO, Maristela. Flexibilidades e salvaguardas do sistema legal de proteção de patentes. In: BASSO, Maristela; SALOMÃO FILHO, Calixto; POLIDO, Fabrício; CESAR, Priscilla. Direitos de propriedade intelectual \& saúde pública: o acesso universal aos medicamentos antirretrovirais no Brasil. São Paulo: IDCID, 2007. p. 121.

(43) BASSO, Maristela; RODRIGUES, Edson. op. cit., p. 53. 
que são matéria de patente no México ou que seja resultado de um processo patenteado, já que o Art. 25 da LPI estabelece como uma das prerrogativas em favor do titular a de opor-se à importação não autorizada.

Dita interpretação, na opinião de Jalife, ${ }^{(44)}$ é inconsistente, já que nada permite estabelecer diferença no tratamento das importações paralelas em matéria de marcas, respeito das patentes, quando os supostos são coincidentes. Isto é, se o produto é importado diretamente do titular da patente ou de algum de seus distribuidores, nada impede que se estabeleça competição com produtos genuínos através da importação realizada por qualquer terceiro que cumpra com as disposições sanitárias aplicáveis. Portanto, de acordo com o Art. 22 da LPI, qualquer importador que introduza no mercado mexicano produtos distinguidos com a mesma marca que é matéria da licença ou distribuição para território nacional pode comercializá-los livremente. Visto de outra perspectiva, se os produtos estão à venda no estrangeiro, por qualquer outro distribuidor licenciado ou pelo próprio titular da patente, podem ser exportados para outro país sem que exista violação alguma de direitos da patente.

\section{EXCEÇÃO BOLAR OU USO EXPERIMENTAL}

\subsection{No Brasil}

No Brasil, a Exceção ou Provisão Bolar, por sua vez, foi incorporada por uma emenda à Lei de Propriedade Industrial, através da Lei Ordinária $n^{\circ}$ $10.196^{(45)}$, que incluiu o inciso VII no Art. 43. O uso dessa flexibilidade tem dupla vantagem para o país: além de favorecer a rápida entrada do medicamento genérico no mercado, possibilita o aprendizado pelo uso da informação sobre a invenção. O uso experimental e a atuação do setor de saúde nos processos de pedidos de patentes farmacêuticas são flexibilidades com reflexos de médio e longo prazo, pois visam estimular o desenvolvimento tecnológico nacional, por meio do aproveitamento do conhecimento disponibilizado pela patente, e impedir que sejam concedidos direitos de exclusividade àqueles pedidos que não atendam aos requisitos legais de patenteabilidade.

Complementarmente, e de forma correta, as autoridades brasileiras rejeitam ajustar o término das patentes outorgadas sob o mecanismo de pipeline. Esse dispositivo constitui uma disposição temporária por meio da qual são aceitos

(44) JALIFE, Mauricio. op. cit.

(45) BRASIL. Lei $\mathrm{n}^{\circ}$. 10.196, de 14 de fevereiro de 2001. "Altera e acresce dispositivos à Lei no 9.279 , de 14 de maio de 1996, que regula direitos e obrigações relativos à propriedade industrial, e dá outras providências". Disponível em: <https://www.planalto.gov.br/ccivil_03/leis/leis_2001/10196. htm>. Acesso em: 10 out. 2012. 
depósitos de patentes em campos tecnológicos não reconhecidos até então, possibilitando a proteção patentária de produtos farmacêuticos e alimentícios, entre outros. Os pedidos de patentes pelo mecanismo pipeline estariam sujeitos apenas a uma análise formal e seguiriam os termos da patente concedida no exterior, não sendo submetidos a uma análise técnica dos requisitos de patenteabilidade - novidade, atividade inventiva e aplicação industrial - pelo escritório de patentes brasileiro - Instituto Nacional de Propriedade Industrial (INPI) - ou, no caso do México, pelo Instituto Mexicano de Propiedad Industrial (IMPI). Dessa forma, se uma patente teve a data de prioridade de sua aplicação nos Estados Unidos a partir de 31 de janeiro de 1987, por exemplo, e foi outorgada no Brasil sob o mecanismo pipeline em 1999, a patente deverá expirar, em ambos os países, no mesmo dia, 30 de janeiro de 2007 . E, ainda que nos Estados Unidos esse prazo pudesse, por exemplo, ser estendido por dois anos, até janeiro de 2009, a patente expiraria no Brasil em 2007. É grande a insistência do setor farmacêutico transnacional para que o ajuste no término de uma patente se estenda também nos outros países, e ele vem demandando isso na justiça, mas essa não é a norma no Brasil. A tendência contra os ajustes de término da patente proporciona incentivos aos produtores de genéricos para utilizar a provisão bolar(46).

\subsection{No México}

Segundo a Tabela 4, o mecanismo de exceção bolar não está considerado na lei mexicana. Por outro lado, Shadlen destaca que ele foi introduzido depois, mas não tem força diante da capacidade do setor transnacional de manter ajustes das datas de expiração das patentes pipeline. A LPI mexicana estipula que as patentes pipeline expiram na mesma data em que expiram no primeiro país em que a patente foi outorgada. Essas cláusulas, embora contestadas em corte, essencialmente obrigam a México a ajustar as datas de expiração conforme isso é feito no país original. Dessa forma, os atores industriais de genéricos não têm condições de saber quando a patente de uma droga expirará, o que implica na perda da vantagem de alguma oportunidade criada pela exceção bolar. ${ }^{(47)}$

\section{A CONCESSÃO DE PATENTES}

No Brasil, a atuação do setor público de saúde no processo de concessão de patentes farmacêuticas foi incorporada pela Lei Ordinária $n^{\circ} 10.196$, que incluiu o Art. 229c na LPI brasileira. Esse dispositivo determina que a concessão de patentes nessa área somente poderá ser concedida com a anuência prévia

(46) SHADLEN, Kenneth. op. cit.

(47) Id. Ibid. 
da Agência Nacional de Vigilância Sanitária (Anvisa), órgão responsável pela segurança sanitária e pela garantia da qualidade dos medicamentos no país. Devido à importância do tema e à essencialidade dos produtos farmacêuticos, o legislador brasileiro entendeu que matéria de tal importância mereceria um exame o mais cuidadoso e tecnicamente competente que o Estado brasileiro pudesse dispor. O papel da Anvisa na anuência prévia não é, assim, o de simples interferência no processo de concessão de patentes. Trata-se de uma medida para proteção dos pacientes, evitando-se que seja concedida uma patente imerecida. A anuência prévia está em perfeita consonância com o Acordo Trips, que em seu Art. $8^{\circ}$ admite que cada membro, ao formular suas leis nacionais, pode adotar medidas que sejam necessárias para a proteção da saúde e promoção do interesse público em setores de vital importância para seu desenvolvimento socioeconômico e tecnológico, como o é o setor de assistência farmacêutica(48).

Por outro lado, no México, a atuação do setor público de saúde no processo de concessão de patentes farmacêuticas é ausente e não existe nenhum mecanismo de atuação governamental nesse processo.

\section{LIMITAÇÕES DA LPI BRASILEIRA E MEXICANA}

Embora o Brasil tenha adotado quase todas as flexibilidades de interesse para a saúde pública previstas no Trips, existem algumas questões tanto na legislação sobre patentes quanto em sua implementação que podem ser consideradas prejudiciais à ampliação do acesso ao tratamento de doenças e à saúde pública em geral. Entre elas, destacam-se as seguintes: mecanismo pipeline; diretrizes de exame de patentes adotadas pelo INPI; dificuldade para implementação do papel do Ministério da Saúde no processo de análise de patentes farmacêuticas (anuência prévia); e medidas Trips-PLUS.

\subsection{Mecanismo pipeline}

Ao alterar sua legislação para satisfazer aos requisitos previstos no Acordo Trips, o Brasil e também o México foram além das obrigações assumidas em âmbito internacional e incluíram na nova legislação um mecanismo de revalidação de patentes depositadas e concedidas no exterior, conhecido como pipeline. A proteção patentária pela via pipeline representa a concessão de privilégios a invenções que já se encontravam em domínio público. O Brasil adota o princípio da novidade absoluta em matéria de patente, ou seja, se a tecnologia para a qual se pede proteção já entrou no estado da técnica em qualquer lugar, em qualquer tempo, não pode ser protegida. As invenções protegidas pelo pipeline

(48) CHAVES, Gabriela; FOGAÇA, Marcela; REIS, Renata. op. cit., p. 178. 
já se encontravam no estado da técnica, uma vez que já haviam sido publicadas no exterior. Como os pedidos de patente foram feitos no Brasil após o término do período de prioridade, as invenções já se encontravam em domínio público e não poderiam mais ser protegidas.

Assim, como afirma Chaves $^{(49)}$, a concessão de patentes pipeline parece violar o princípio da inderrogabilidade do domínio público, pelo qual um conhecimento, após ter entrado em domínio público, não pode mais dele ser retirado. O ingresso no domínio público faz com que determinado bem se torne comum a todos e a coletividade adquire o direito de mantê-lo disponível, impedindo sua apropriação individual. No caso das patentes pipeline, foi possível a proteção retroativa para objetos depositados ou já patenteados em outros países, dentro ou fora do período de anterioridade. Assim, permitiu-se a concessão de patentes para conhecimentos que já tinham patentes conhecidas no exterior mesmo antes do momento zero do Trips. Além disso, as patentes pipeline não passam por nenhuma análise técnica no escritório de patentes brasileiro.

Miranda et al. acrescentam um argumento acerca da inconstitucionalidade do mecanismo pipeline: ele contraria o princípio da isonomia, ao permitir tratamento diferenciado entre nacionais e estrangeiros, na medida em que o depósito do inventor nacional só foi aceito mediante o preenchimento dos requisitos de patenteabilidade estabelecidos na lei nacional (Art. $8^{\circ}$, Lei $n^{\circ} 9.279$ ), enquanto os depositantes estrangeiros foram submetidos apenas aos requisitos exigidos nos países de origem, que em muitos casos se diferenciam dos previstos no Brasil, podendo ter sua patente concedida mesmo sem preencher os requisitos exigidos localmente. Essa situação traz graves distorções ao sistema, tendo em vista que alguns países sequer realizam exame técnico. ${ }^{(50)}$

Paralelamente, no México, o mesmo dispositivo pipeline também foi legislado (Art. 12 transitório). Desde a promulgação da LPI mexicana, muitos especialistas mexicanos consideram que a proteção de patentes sob esse regime (pipeline) viola a Constituição mexicana, por dar efeito retroativo a uma normativa, em detrimento de laboratórios nacionais e do público consumidor, já que se outorgava proteção a invenções que, no México, já eram de domínio público. ${ }^{(51)}$

Jaime Uribe ${ }^{(52)}$ argumenta que, uma vez ampliado o espectro de patenteabilidade para áreas novas, as grandes potências pressionaram para a adoção do sistema pipeline, que não é outra coisa senão uma "resurrección de patentes", o

(49) CHAVES, Gabriela; FOGAÇA, Marcela; REIS, Renata. op. cit., p. 181.

(50) MIRANDA, Pedro; SILVA, Francisco Neves da; PEREIRA, Amanda. Perguntas e respostas sobre patentes pipeline: como afetam sua saúde? Rio de Janeiro: ABIA, 2009. 21 p.

(51) JALIFE, Mauricio. op. cit.

(52) URIBE, Jaime. Las reformas de las leyes de patentes en la industria farmacêutica de México. In: GUZMAN, Alenka; VINIEGRA, Gustavo. Industria farmacêutica y propiedad intelectual: los países em desarrollo. México: Universidad Autónoma Metropolitana, 2005. p. 326. 
resgate ao "mundo dos monopólios artificiais" de invenções de áreas da ciência e tecnologia que tinham caído em domínio público. O México cedeu à pressão pela adoção da pipeline e excedeu o esquema e os requisitos adotados por outros países que também incorporaram esse sistema. $\mathrm{O}$ argumento que sustenta a necessidade deste artigo foi o discurso de incentivo aos grandes laboratórios transnacionais que investem somas vultosas em pesquisa e desenvolvimento (P\&D) para a criação de medicamentos. Uribe afirma que os beneficiários do regime de exceção foram as empresas transnacionais e estrangeiras. Apresentaram em torno de 800 solicitações, muitas das quais foram outorgadas sem qualquer análise. Assim, segundo o autor, o investimento esperado das empresas promotoras do pipeline não se traduziu, como anunciado, na abertura de fábricas e centros de P\&D de ponta, mas sim em aumento das importações do produto terminado por parte das grandes transnacionais. Na opinião dele, "é, precisamente, esta dolorosa e negligente cumplicidade que tem sido gerada pelas autoridades patentárias em países desenvolvidos e, por submissão, em países em desenvolvimento que tem dado lugar à 'farmacocracia', com consequências custosas para a sociedade".

No Brasil, as patentes pipeline também causaram grande impacto em áreas sensíveis para o interesse social e para o desenvolvimento tecnológico e econômico do país. De acordo com os dados divulgados pelo INPI, dentro do prazo legal de um ano, a contar da publicação da Lei $n^{\circ} 9.279$, foram depositados 1.182 pedidos pipeline, dos quais mais da metade já foi concedida e os demais estão em andamento. O Efavirenz, medicamento recentemente licenciado de forma compulsória, é protegido por uma patente obtida através do mecanismo pipeline. Ou seja, quando esse medicamento foi depositado no Brasil, não mais atendia ao requisito de novidade (pois a informação sobre a invenção já havia sido publicada no exterior cinco anos antes). Esse princípio ativo poderia ter sido fabricado no Brasil, tal como foi na Índia. Outros medicamentos fundamentais para uma resposta adequada à epidemia de HIV/ AIDS, a exemplo do Lopinavir/Ritonavir, Abacavir, Nelfinavir e Amprenavir, também foram protegidos pelo pipeline, assim como o medicamento para câncer - Imatinib ou Glivec (nome comercial). ${ }^{(53)}$

Um parecer técnico elaborado por conceituados economistas dimensiona o prejuízo hipotético causado pela adoção do mecanismo pipeline pelo Brasil, nas compras governamentais de cinco medicamentos ARVs utilizados no tratamento da AIDS ocorridas entre 2001 e 2007. Os dados revelam que o Brasil gastou entre 420 milhões de dólares (se comparados com os preços mínimos da OMS) e 519 milhões de dólares (comparando com preços mínimos da organização Médicos sem Fronteiras) a mais, apenas com a compra desses cinco medicamentos $\mathrm{ARVs}^{(54)}$.

(53) CHAVES, Gabriela; FOGAÇA, Marcela; REIS, Renata. op. cit., p. 181.

(54) VIEIRA, Marcela; MACHADO, Eloísa (Orgs.). Acesso a medicamentos: audiência pública sobre saúde. Rio de Janeiro: ABIA, 2009. p. 15. 


\subsection{Diretrizes de exame de patentes adotadas pelo INPI}

No Brasil, o INPI, autarquia federal vinculada ao Ministério do Desenvolvimento, Indústria e Comércio Exterior criada em 1970, tem por finalidade executar as normas que regulam a propriedade intelectual, tendo em vista a sua função social, econômica, jurídica e técnica, de acordo com a LPI e com a Constituição Federal. Desse modo, cabe ao INPI analisar pedidos de concessão de patentes em diversas áreas do conhecimento, inclusive medicamentos. Para a análise de pedidos de patentes de medicamentos, o INPI emitiu as "Diretrizes para o exame de pedidos de patente nas áreas de biotecnologia e farmacêutica depositadas após 31/12/1994"(55). Ao lado da LPI, as diretrizes de patenteabilidade para invenções farmacoquímicas e biotecnológicas do INPI, na opinião de vários especialistas, ${ }^{(56)}$ constituem imensos obstáculos legais ao desenvolvimento da capacidade tecnológica da indústria biofarmacêutica brasileira. O INPI adota a política contra legem de proteção de inovações incrementais, ou seja, concede proteção patentária para invenções abrangendo derivados de drogas, sais conhecidos, drogas antigas apresentadas em diferentes dosagens, drogas conhecidas apresentadas em novas formas de administração, combinações de produtos conhecidos (incluindo combinações de dose fixa), novos usos de drogas/compostos já conhecidos.

Por outra parte, o sistema brasileiro de exame de patentes biofarmacêuticas é complexo e único no mundo, porquanto envolve tanto o INPI quanto a Anvisa, constituindo a práxis da Anvisa de exame de patentes farmacêuticas um importante contraponto à política do INPI, ao robustecer os patamares de patenteabilidade (dentro das flexibilidades permitidas pelo Acordo Trips e pela LPI), conservando no domínio público informações que - se aplicadas integralmente às diretrizes do INPI - seriam injustificadamente mantidas sob o controle de poucos.

No caso do México, a Secretaria de Economia, por mandato da Ley Orgánica de Administración Publica Federal, tem o encargo de "normatizar e registrar a propriedade industrial e mercantil e a transferência de tecnologia". (57) O IMPI -entidade equivalente ao INPI brasileiro -, autoridade administrativa em matéria de propriedade industrial, é um organismo descentralizado com personalidade jurídica e patrimônio próprio (Art. 6 da LPI mexicana). Entretanto, a regulamentação da dita lei expressa que essa disposição tem a finalidade de determinar a organização e competência das autoridades do IMPI, para o exercício das atribuições que lhe confere a LPI mexicana ${ }^{(58)}$. Alguns especialistas mexicanos também concordam que a regulamentação da proteção à inovação,

(55) CHAVES, Gabriela; FOGAÇA, Marcela; REIS, Renata. op. cit., p. 182.

(56) BASSO, Maristela; RODRIGUES, Edson. op. cit., p. 53.

(57) LABARIEGA, Pedro. Algunas consideraciones sobre el derecho de propiedad intelectual en México. Revista de Derecho Privado, Madrid, ano 2, n. 6, p. 25-59, set./dez. 2003.

(58) RANGEL, David. op. cit., p. 22. 
no que diz respeito às patentes de fármacos e processos, na forma que está materializada pela LPI mexicana, gera condições de controle de preços que se contrapõem ao ideal de livre concorrência para a obtenção de melhores preços e opções de mercado. ${ }^{(59)}$

\subsection{Anuência prévia da Anvisa}

De acordo com a LPI brasileira, pedidos de patentes farmacêuticas precisam obter a anuência prévia da Anvisa, tendo em vista a sua importância para a saúde pública. O principal problema na implementação desse controle consiste no fato de que o INPI não publica as decisões da Anvisa contrárias ao pedido, impedindo a finalização completa do processo de não concessão da patente. Isso significa que o pedido de patente continua pendente e o potencial detentor desta goza de um monopólio "de fato" de qualquer jeito. ${ }^{(60)}$

No México, como dito, não existe nenhuma instituição com características de função similar à Anvisa.

\subsection{Projetos de lei Trips-PLUS}

No caso do Brasil, atualmente, estão em trâmite no Congresso Nacional diversos projetos de lei que, se aprovados, representarão a incorporação de medidas Trips-PLUS na legislação brasileira. Exemplo disso é o Projeto de Lei n² 29/06, que visa à inclusão de uma medida Trips-PLUS ao prever a vinculação entre a proteção patentária e o registro sanitário do medicamento. Se aprovado, significa que, na prática, a Exceção Bolar prevista na legislação brasileira será anulada.

Porém, cabe mencionar aqui o recente estudo apresentado por Marcela $V_{\text {Vieira }}{ }^{(61)}$ sobre a adequação legislativa sob a ótica da saúde pública e do direito humano à saúde. Essa análise considerou as obrigações assumidas pelo Brasil em tratados internacionais de propriedade intelectual para produtos e processos farmacêuticos, as medidas de proteção que poderiam ser adotadas para minimizar os efeitos negativos destas obrigações e também as medidas que vão além delas (dispositivos Trips-PLUS). Os resultados parciais mostram que a legislação do país não adota todas as medidas de proteção previstas internacionalmente e que algumas destas medidas são adotadas de forma bastante restrita, como é o caso da possibilidade de se fazer oposição a um

(59) JALIFE, Mauricio. op. cit.

(60) CHAVES, Gabriela; FOGAÇA, Marcela; REIS, Renata. op. cit., p. 180.

(61) VIEIRA, Marcela; CONECTAS. Propriedade intelectual para produtos farmacêuticos: um estudo sobre a adequação legislativa sob a ótica da saúde pública e do direito humano à saúde. Abr. 2011. Disponível em: <http://www.deolhonaspatentes.org.br/media/file/seminario\%20abril\%202011/ Marcela\%20Vieira\%20-\%20legislacao.pdf>. Acesso em: 10 out. 2012. 
pedido de patente. Em relação às medidas que vão além das obrigações internacionais e podem ser consideradas prejudiciais à saúde pública, por afetarem o acesso a medicamentos, cinco delas foram adotadas no Brasil: pipeline, extensão de prazo e exclusividade de dados constam na lei. Já a possibilidade de proteção de um novo uso de um produto conhecido ou de formas polimórficas de uma substância constam nas diretrizes de exame do INPI. No mesmo estudo Vieira analisou ainda os projetos de lei que tramitam no Congresso e identificou quatro potencialmente prejudiciais à proteção da saúde pública e 12 potencialmente favoráveis.

Por outro lado, no caso do México, com respeito à extensão de vigência patentária, Jalife afirma que muitos dos titulares de patentes tramitadas conforme o Art. 12 transitório apresentaram solicitações ao IMPI, durante $2001 \mathrm{e}$ 2002, de prorrogação de suas patentes, e foram atendidos. Porém, recentemente, o instituto tem mudado sua política, passando a negar a outorga das extensões da vigência. ${ }^{(62)}$

Adicionalmente, em 19 de novembro de 2003, foi publicada a reforma que o Executivo realizou no Reglamento de Insumos para la Salud e no Reglamento LPI, motivo de ampla polêmica. Em conformidade com tal texto, o próprio decreto insere o Art. 47 bis no Reglamento de $L P I$, que formaliza o chamado "sistema de vínculo" (linkage). De acordo com essa reforma, a outorga de um registro sanitário fica sujeita à verificação de que a comercialização do produto não incorra em infração de uma patente vigente, o que implica em violação do sistema normativo. Existindo ampla matéria sobre a questão, basta assinalar que uma reforma como essa incide em várias irregularidades, a partir da falta de justificativa para vincular os temas de patentes a temas sanitários, dada a diversidade da natureza jurídica de ambas as legislações mexicanas. A reforma supõe também uma clara violação constitucional, já que, no exercício da faculdade regulamentar que compete ao Executivo, se promulga um preceito que excede as exigências da lei. A negativa de outorgar um registro sanitário a uma empresa, quando seu produto cumprir cabalmente as disposições sanitárias, apenas por existir uma patente, constitui uma restrição que implica em uma condenação prévia por uma violação que não tem sido determinada em juízo, o que constitui uma privação dos mais elementares direitos de livre comércio ${ }^{(63)}$.

Shadlen opina que, através dessa medida, o setor transnacional também assegurou mudanças favoráveis para suas empresas, quanto à entrada de medicamentos genéricos. Dessa maneira, em setembro de 2003, quando o governo Fox anunciou um novo sistema de linkage, o resultado apontou que, enquanto a medida de consentimento prévio no Brasil integra o critério de saúde

(62) JALIFE, Mauricio. op. cit.

(63) Id. Ibid. 
na política de patentes, o sistema de linkage no México subordina a política de saúde ao sistema de patente. ${ }^{(64)}$

Além disso, ainda mais recentemente, decisões judiciais têm estendido a vigência das patentes acima de 20 anos, provocando um prejuízo econômico de 15 bilhões de pesos mexicanos (1,2 bilhão de dólares), cálculo feito pela Asociación Nacional de Fabricantes de Medicamentos (Anafan). Na opinião de Dagoberto Cortés, presidente de Anafan, o efeito será mais devastador para a população geral e o Estado mexicano do que para os produtores de genéricos, porque as instituições do setor de saúde terão que comprar medicamentos mais caros, representando um retrocesso significativo no processo de barateamento dos medicamentos. Sua opinião coincide com a de Ricardo Romay, presidente da Asociación Mexicana de Laboratorios Farmacéuticos (Amelaf). Para ambas as associações, a decisão do Tribunal Superior de Justiça do México somente beneficia os laboratórios transnacionais, ao estender a vigência das patentes quando seus princípios ativos sejam utilizados em novas fórmulas de composição ou reformulação, o que supera inclusive os limites de vigência de patentes estabelecidos pelo Acordo Trips e o Nafta ${ }^{(65)}$.

Para finalizar esta análise comparativa, apresentamos um gráfico acerca do grau de sensibilidade à saúde pública das LPI brasileira e mexicana, a partir dos dados e da metodologia de mensuração proposta no estudo de Chaves \& Oliveira ${ }^{(66)}$, a mesma que pontua a presença de flexibilidades ou salvaguardas e de dispositivos Trips-PLUS dentro das respectivas LPI. Naquele estudo com 15 países da América Latina, o Paraguai ficou em primeiro lugar, ou seja, sua legislação sobre propriedade industrial apresentou maior grau de sensibilidade à saúde pública (score de 86,9) e o Panamá ficou em último (score de 43,6). O Brasil ficou em muito melhor posição comparado ao México, confirmando a mesma tendência subjetiva que nós aqui consideramos (Gráfico 1). Cabe lembrar novamente que este estudo teve como referência a LPI 1996 do Brasil e a LPI 1999 do México e que, portanto, modificações adicionais relacionadas a provisões Trips-PLUS discutidas anteriormente poderiam rebaixar ainda mais a pontuação do México, ampliando a diferença com o Brasil.

\section{CONSIDERAÇÕES FINAIS}

Como podemos observar pelo que foi exposto até agora neste estudo, é possível concluir que, embora tanto Brasil como México tenham modificado

(64) SHADLEN, Kenneth. op. cit., p. 58.

(65) MARES, Marco. Golpea Corte com US 15,000 millones al sector salud. El Economista. Disponível em: <http://eleconomista.com.mx/columnas/columna-especial-valores/2010/01/19/golpea-corte15000-millones-sector-salud>. Acesso em: 10 out. 2012.

(66) CHAVES, Gabriela; OLIVEIRA, Maria. op. cit., p. 49-56. 
Gráfico 1: Grau de sensibilidade à saúde da legislação de patentes de Brasil e México

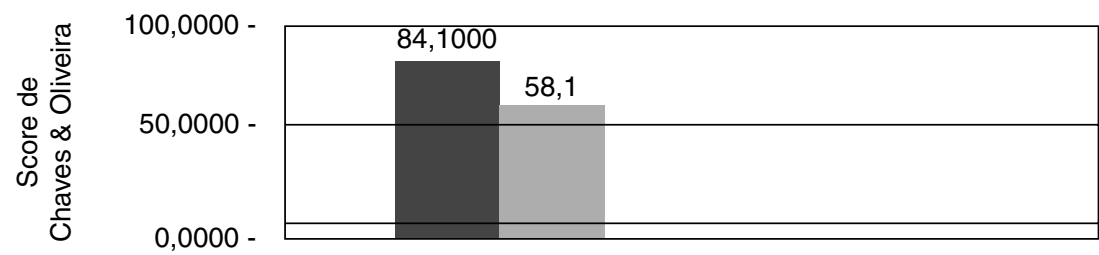

Brasil México

\begin{tabular}{|lc|}
\hline PROVISÕES LEGAIS & SCORE \\
\hline $\begin{array}{l}\text { Flexibilidades } \\
\text { Licença compulsória }\end{array}$ & 14,7 \\
$\begin{array}{l}\text { Participação do Ministério da Saúde na análise de pedidos de } \\
\text { patentes farmacêuticas }\end{array}$ & 13,1 \\
\hline $\begin{array}{l}\text { Importação paralela } \\
\text { Exceção Bolar (early working) }\end{array}$ & 12,4 \\
\hline $\begin{array}{l}\text { Uso experimental } \\
\text { Período de transição para outorgar patentes farmacêuticas }\end{array}$ & 11,1 \\
\hline $\begin{array}{l}\text { Provisões Trips-PLUS } \\
\text { Não inclui extensão do término da patente (além de 20 anos) }\end{array}$ & 7,5 \\
$\begin{array}{l}\text { Não inclui vínculo entre aprovação para introdução da droga no } \\
\text { mercado e status da patente }\end{array}$ & 5,3 \\
\hline $\begin{array}{l}\text { Não inclui exclusividade de dados submetidos para registro dos } \\
\text { fármacos }\end{array}$ & 13,2 \\
\hline Total & 13,2 \\
\hline
\end{tabular}

suas LPI para implementar o Acordo Trips (e, no caso do México, também o Nafta) e apesar de terem tido um início muito similar nos anos 1990, houve algumas mudanças significativas nas duas últimas décadas. Essas modificações levaram a maior proteção dos direitos dos detentores de patente e a patamares mais elevados de proteção de propriedade intelectual (incluindo o industrial) no México quando comparado ao Brasil. E isso pode ter-se traduzido num maior efeito positivo sobre a saúde pública por parte do Brasil, se comparado ao que aconteceu no México, especificamente para um menor rendimento e eficácia do seu programa de combate à epidemia de HIV/AIDS, já que, para dar uma cobertura mais adequada de tratamento com ARV a sua população, teve que enfrentar maiores dificuldades para a aquisição dos 
medicamentos. Assim como o Brasil, embora mais tardiamente, o México também optou por oferecer acesso universal ao tratamento ARV, mas, ao contrário do que aconteceu no Brasil, a ausência de certas flexibilidades, como a emissão de licença compulsória para produção nacional de ARVs genéricos, impediu as entidades governamentais do setor de saúde mexicano de utilizarem essas salvaguardas como armas de negociação perante os laboratórios transnacionais detentores das patentes, para diminuição de preços dos medicamentos. Tudo isso pode ter refletido não somente em uma cobertura de tratamento ARV menos abrangente e mais cara comparada à do Brasil, mas, também, ao final, em uma relativa maior mortalidade dos pacientes com HIV AIDS, comparada à brasileira, como mostrado recentemente em outro estudo. ${ }^{(67)}$

O Brasil se diferenciou do México logo de início por ter permitido que, diante das repercussões negativas sobre a saúde pública da sua LPI pós-Trips, forças sociais e políticas organizadas questionassem a lei, levando as autoridades governamentais a modificá-la em defesa da saúde pública. Porém, paradoxalmente, o Brasil, apesar de ter tido um claro papel protagonista na questão da propriedade intelectual em defesa da saúde pública, ainda sim, de certa maneira, teve um desempenho ambíguo se considerarmos certas características de sua LPI, como o mecanismo pipeline, por exemplo, ou as diretrizes do INPI, favoráveis aos detentores das patentes. O que só demonstra a complexidade do problema e as diversas zonas de conflito em que os diferentes atores se enfrentaram.

No substrato dos fatores causais dessas divergências, podem ser considerados diversos fatores de natureza econômica e política, dentre eles a maior ou menor magnitude da influência política dos Estados Unidos e interesses econômicos de suas empresas transnacionais sobre ambos os países. Descrito de uma perspectiva da ciência política, após a queda do Muro de Berlim e findada a Guerra Fria, Brasil e México (assim como outros países em desenvolvimento) foram envolvidos pela onda da globalização, do neoliberalismo e da retomada da hegemonia norte-americana, sendo uma consequência disso a criação da $\mathrm{OMC}$ e a assinatura do Acordo Trips, que resultariam na implementação das respectivas LPI de ambos os países. Só que a influência dos Estados Unidos sobre o México, que é real, histórica, profunda e complexa, determinou maior influência dos interesses econômicos dos laboratórios transnacionais americanos no país.

(67) ACOSTA-NAVARRO, Julio. Direito de patentes vs. direito à vida: a epidemia da AIDS no contexto do Acordo Trips. Curitiba: Juruá, 2012. 194 p. 


\section{REFERÊNCIAS}

ACOSTA-NAVARRO, Julio. Direito de patentes vs. direito à vida: a epidemia da AIDS no contexto do Acordo Trips. Curitiba: Juruá, 2012.

BASSO, Maristela. Flexibilidades e salvaguardas do sistema legal de proteção de patentes. In: BASSO, Maristela; SALOMÃO FILHO, Calixto; POLIDO, Fabrício; CESAR, Priscilla. Direitos de propriedade intelectual \& saúde pública: o acesso universal aos medicamentos antirretrovirais no Brasil. São Paulo: IDCID, 2007.

; RODRIGUES, Edson. Avaliação legal. In: ROSSI, Francisco (Org.). Avaliação técnica, econômica e legal de capacidade de produção de antirretrovirais no Brasil. Brasília-DF: PNUD, 2008.

; SALOMÃO FILHO, Calixto; POLIDO, Fabrício; CESAR, Priscilla. Direitos de propriedade intelectual \& saúde pública: o acesso universal aos medicamentos antirretrovirais no Brasil. São Paulo: IDCID, 2007.

BERMUDEZ, Jorge; OLIVEIRA, Maria Auxiliadora; CHAVES, Gabriela. O Acordo Trips da OMC e os desafios para a saúde pública. In: BERMUDEZ, Jorge; OLIVEIRA, Maria Auxiliadora; ESHER, Ângela (Coords.). Acesso a medicamentos: direito fundamental, papel do Estado. Rio de Janeiro: ENSP, 2004.

CEPALUNI, Gabriel. Regimes internacionais e o contencioso das patentes para medicamentos: estratégias para países em desenvolvimento. Contexto Internacional, Rio de Janeiro, v. 27, n. 1, 2005.

CHAVES, Gabriela. Patentes farmacêuticas: por que dificultam o acesso a medicamentos? Rio de Janeiro: Associação Brasileira Interdisciplinar de AIDS, 2006.

; FOGAÇA, Marcela; REIS, Renata. Acesso a medicamentos e propriedade intelectual no Brasil: reflexões e estratégias da sociedade civil. Revista Internacional de Direitos Humanos, São Paulo, v. 5, n. 8, p. 151192, 2008.

; OLIVEIRA, Maria. A proposal for measuring the degree of public health sensitivity of patent legislation in the context of the WTO Trips Agreement. Bulletin of the World Health Organization, v. 85, n. 1, p. 49-56, Jan. 2007.

COHEN-KOHLER, Jillian Clare; FORMAN, Lisa; LIPKUS, Nathaniel. Addressing legal and political barriers to global pharmaceutical access: options for remedying the impact of the Agreement on Trade-Related Aspects of Intellectual Property Rights (Trips) and the imposition of TRIP-plus standards. Health Economics, Policy and Law, v. 3, n. 3, p. 219-228, Jul. 2008. 
CORREA, Marilena; CASSIER, Maurice. Saúde pública, ciência e indútria: os programas industriais de cópia de medicamentos contra AIDS em laboratórios farmacêuticos brasileiros e a política de acesso universal ao tratamento. In: CORREA, Marilene; CASSIER, Maurice (Org.). AIDS e saúde pública: contribuições à reflexão sobre uma nova economia política do medicamento no Brasil. Rio de Janeiro: Ed. UERJ, 2010.

FORMENTI, Ligia. Farmacêuticas reagem a discurso de Dilma. O Estado de $S$. Paulo, São Paulo, 21 set. 2011. A18.

FORNETTI Verena; FAGUNDES Alvaro. ONU pede prioridade para combate a doenças crônicas. Folha de S. Paulo, São Paulo, 20 set. 2011. C14.

GUISE, Mônica. O requisito de exploração local do objeto da patente: uma análise da legislação no contexto internacional. In: CARVALHO, Patrícia (Org.). Propriedade intelectual: estudos em homenagem à professora Maristela Basso. Curitiba: Juruá, 2005.

JALIFE, Mauricio. Análisis de aspectos legales y comerciales de las patentes de medicamentos en México. Biblioteca Jurídica Virtual del Instituto de Investigaciones Jurídicas de la UNAM. Disponível em: <http://biblio.juridicas. unam.mx/libros/6/2634/6.pdf>. Acesso em: 10 out. 2012.

LABARIEGA, Pedro. Algunas consideraciones sobre el derecho de propiedad intelectual en México. Revista de Derecho Privado, Madrid, ano 2, n. 6, p. 2559, set./dez. 2003.

LOYOLA, Maria Andréa. Aids e saúde pública: a implantação de medicamentos genéricos no Brasil. In: CORREA, Marilene; CASSIER, Maurice (Orgs.). AIDS e saúde pública: contribuições à reflexão sobre uma nova economia política do medicamento no Brasil. Rio de Janeiro: Ed. UERJ, 2010.

. Medicamentos e saúde pública em tempos de AIDS: metamorfoses de uma política dependente. Ciência \&. Saúde Coletiva, São Paulo, v. 13, suppl., p. 763-778, 2008. Disponível em: <http://www.scielo.br/scielo.php?pid=S1413$81232008000700027 \&$ script=sci_arttext>. Acesso em: 10 out. 2012.

; VILELA, Pedro; GUIMARÂES, Eduardo. Medicamentos e patentes na ordem do dia: a mídia e "a guerra de patentes". In: CORREA, Marilene; CASSIER, Maurice (Orgs.). AIDS e saúde pública: contribuições à reflexão sobre uma nova economia política do medicamento no Brasil. Rio de Janeiro: Ed. UERJ, 2010.

MARES, Marco. Golpea Corte com US 15,000 millones al sector salud. El Economista. Disponível em: <http://eleconomista.com.mx/columnas/columnaespecial-valores/2010/01/19/golpea-corte-15000-millones-sector-salud>. Acesso em: 10 out. 2012.

MIRANDA, Pedro; SILVA, Francisco Neves da; PEREIRA, Amanda. Perguntas e respostas sobre patentes pipeline: como afetam sua saúde? Rio de Janeiro: ABIA, 2009. 21p. 
OLIVEIRA, Marcelo de. Multilateralismo, democracia e política externa no Brasil: contenciosos das patentes e do algodão na Organização Mundial de Comércio. Contexto Internacional, Rio de Janeiro, v. 29, n. 1, 2007.

OLIVEIRA, Maria; BERMUDEZ, Jorge; CHAVES, Gabriela; VELASQUES, German. Has the implementation of the Trips agreement in Latin America and the Caribbean produced intellectual property legislation that favors public health? Bulletin of the World Health Organization, v. 82, n. 11, p. 811-889, Nov. 2004.

OXFAM. Patentes contra pacientes: cinco años después de la Declaración de Doha. Disponível em: <http://www.slideshare.net/guest292ba1/patentes-vspacientes-2951185>. Acesso em: 10 out. 2012.

RANGEL, David. Derecho de la propiedad industrial e intelectual. México: Universidad Nacional Autónoma de México, 1992.

SATYANARAYANA, K. Trips, patents \& HIV/AIDS drugs. Indian J Med Res, v. 121, n. 4, p. 211-214, 2005.

SHADLEN, Kenneth. The politics of patents and drugs in Brazil and Mexico: the industrial bases of health policies. Comparative Politics, New York, v. 42, n. 1, p. 41-58, 2009. Disponível em: <http://eprints.lse.ac.uk/27051/>. Acesso em: 10 out. 2012.

URIBE, Jaime. Las reformas de las leyes de patentes en la industria farmacêutica de México. In: GUZMAN, Alenka; VINIEGRA, Gustavo. Industria farmacêutica y propiedad intelectual: los países em desarrollo. México: Universidad Autónoma Metropolitana, 2005.

VIEIRA, Marcela; CONECTAS. Propriedade intelectual para produtos farmacêuticos: um estudo sobre a adequação legislativa sob a ótica da saúde pública e do direito humano à saúde. Abr. 2011. Disponível em: <http://www.deolhonaspatentes.org.br/media/file/seminario\%20abril\%202011/ Marcela\%20Vieira\%20-\%20legislacao.pdf>. Acesso em: 10 out. 2012.

; MACHADO, Eloísa (Orgs.). Acesso a medicamentos: audiência pública sobre saúde. Rio de Janeiro: ABIA, 2009.

WORLD BANK. World Bank warning: AIDS to cause complete economic collapse within 3 generations. South African Medical Journal, v. 93, n. 10, p. 745-746, 2003. 